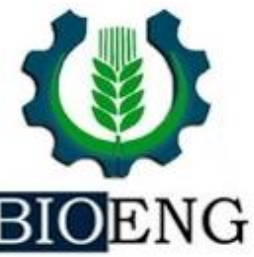

\title{
DOSES DE FÓSFORO E POTÁSSIO EM PLANTAS DE AMENDOIM NA PRESENÇA E AUSÊNCIA DE ADUBAÇÃo FOLIAR
}

\author{
H. H. A. Meneghette*, E. Lazarini, J. W. Bossolani, L. F. Parra,
} F. K. Hayashi

UNESP - Univ Estadual Paulista, Faculdade de Engenharia, Campus de Ilha Solteira, SP, Brasil

Article history: Received 14 January 2017; Received in revised form 20 April 2017; Accepted 24 April 2017; Available online 30 June 2017.

\section{RESUMO}

Desejando-se avaliar o desempenho agronômico da cultura do amendoim submetido a diferentes doses de fósforo e potássio juntamente da presença ou ausência de aplicação de adubo foliar, desenvolveu-se 2 experimentos na Fazenda de Ensino, Pesquisa e Extensão/UNESP - Campus de Ilha Solteira, localizada no município de Selvíria - MS. O delineamento experimental utilizado foi em blocos casualizados com 4 repetições, sendo os tratamentos dispostos em esquema fatorial $3 \times 3 \times 2$, sendo 3 doses de fósforo $(0,60$ e $120 \mathrm{~kg}$ ha $^{-1}$ de $\left.\mathrm{P}_{2} \mathrm{O}_{5}\right)$ e 3 doses de potássio $\left(0,20\right.$ e $40 \mathrm{~kg} \mathrm{ha}^{-1}$ de $\left.\mathrm{K}_{2} \mathrm{O}\right)$ via solo, e ausência ou presença do adubo foliar Flonergan ${ }^{\circledR}\left(1 \mathrm{~L} \mathrm{ha}^{-1}\right)$. Foi utilizado o cultivar IAC-Tatu ST, utilizando espaçamento de $0,9 \mathrm{~m}$, com semeaduras realizadas em 16 junho e 14 novembro de 2006 para o Experimento 1 e 2, respectivamente. Para o Experimento 1, o parâmetro massa de 100 grãos apresentou interação significativa para doses de fósforo $\mathrm{x}$ adubo foliar, destacandose o tratamento constituído por presença de adubo foliar na dose de $60 \mathrm{~kg} \mathrm{ha}^{-1} \mathrm{P}_{2} \mathrm{O}_{5}$. No Experimento 2, observa-se que a dose de $20 \mathrm{~kg} \mathrm{ha}^{-1}$ de $\mathrm{K}_{2} 0$ causou um incremento superior na massa de 100 grãos. Não foi constatado aumento da produtividade de grãos de amendoim até as doses de fósforo e potássio utilizadas.

Palavras-chave: Arachis hypogaea L., produtividade de grãos, nutrição mineral.

\section{DOSES OF PHOSPHORUS AND POTASSIUM IN PEANUT PLANT IN THE PRESENCE AND ABSENCE OF FOLIAR FERTILIZATION}

\begin{abstract}
Wishing to evaluate agronomic performance of peanut crop submitted to different doses of phosphorus and potassium together with the presence and absence of application of leaf fertilizer, 2 experiments were developed on Fazenda de Ensino, Pesquisa e Extensão/UNESP - Ilha Solteira Campus, located in the municipality of Selvíria - MS. The experimental design used was in randomized blocks with 4 replicates, Being the treatments arranged in factorial

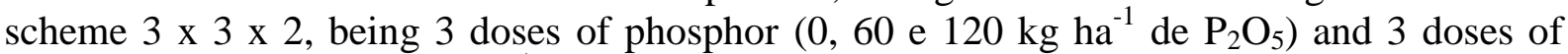
potassium $\left(0,20\right.$ e $40 \mathrm{~kg} \mathrm{ha}^{-1}$ de $\left.\mathrm{K}_{2} \mathrm{O}\right)$ by way of soil, and absence or presence of leaf fertilizer Flonergan ${ }^{\circledR}\left(1 \mathrm{~L} \mathrm{ha}^{-1}\right)$. The cultivar used was the IAC-Tatu ST, with spacing of 0,9 m. With sowing performed in June 16 and November 14, 2006 for the Experiment 1 and 2, respectively. For Experiment 1, the mass parameter of 100 grains presented significant interaction or doses of phosphorus $\mathrm{x}$ foliar fertilizer, especially the treatment constituted by the presence of foliar fertilizer at the dose of $60 \mathrm{~kg} \mathrm{ha}-1 \mathrm{P}_{2} \mathrm{O}_{5}$. In Experiment 2, it is observed
\end{abstract}


that the dose of $20 \mathrm{~kg}$ ha-1 of K20 caused a larger increase in the mass of 100 grains. No increase in peanut grain yield was observed until the doses of phosphorus and potassium used.

Keywords: Arachis hypogaea L., grains productivity, mineral nutrition.

\section{INTRODUÇÃO}

O amendoim é uma planta cultivada em toda extensão do território nacional, cujo valor de mercado interno e externo, rende bons lucros ao produtor. A produção aumentou expressivamente nos últimos anos, alcançando 350 mil toneladas em 2016 (CONAB, 2017). Neste contexto, parte da produção é exportada ou destinada à indústria de alimentos - mais de $80 \mathrm{mil}$ toneladas em 2013 (MARTINS, 2015). A produção de amendoim brasileiro é oriunda, em maior escala, da região sudeste, seguida pelo centro-oeste, onde São Paulo destaca-se por ser o maior estado produtor (MACÊDO, 2006).

$\mathrm{O}$ cultivo de amendoim assume maior importância, em áreas de renovação de pastagens e reforma de canaviais, pois o amendoim aproveita grande parte dos resíduos de adubação desses tipos de cultivo, sendo recomendado em sistema de rotação (HENN, 2013).

A nutrição de plantas via adubação mineral é considerado um fator importante em seu desenvolvimento e no aumento de produção. Assim sendo, o fornecimento adequado e balanceado de nutrientes é essencial para favorecer ganhos significativos de produção. O fósforo é crucial no metabolismo da planta, uma vez que atua na transferência de energia na

\section{MATERAL E MÉTODO}

Foram instalados em campo dois experimentos ( 1 e 2 ) no período de abril de 2006 a março de 2007, na área experimental da Fazenda de Ensino, Pesquisa e Extensão da Faculdade de Engenharia/ Universidade Estadual Paulista - Campus Ilha Solteira, localizada no município de Selvíria - MS, localizado nas coordenadas geográficas $51^{\circ} 22^{\prime} \mathrm{W}$ e $20^{\circ} 22^{\prime} \mathrm{S}$ e altitude aproximada de $335 \mathrm{~m}$. célula, na taxa respiratória, fotossíntese, compõe estruturas de ácidos nucléicos, genes, cromossomos assim como diversas coenzimas (GRANT, 2001). Desta forma, este nutriente é importante no crescimento inicial das raízes e tem função básica na promoção de desenvolvimento de sementes (MARQUES, 2014).

O potássio também tem alto grau de importância no desenvolvimento vegetal, pois é um controlador dos movimentos estomáticos e ativador metabólico essencial para formação de proteínas, mesmo não possuindo função estrutural ou metabólica (HESS, 2015).

A adubação e nutrição do amendoim, no entanto continuam sendo um assunto discutível, uma vez que, apesar da grande capacidade de extração de nutrientes do solo apresentada por esta espécie vegetal, as respostas a critérios de fertilização a ela aplicados não puderam ainda ser generalizados, principalmente pelo grande poder de aproveitamento de adubações anteriores (HERNANDEZ et al., 1993).

Neste contexto, o objetivo do presente trabalho foi avaliar o desempenho agronômico da cultura do amendoim submetido a diferentes doses de fósforo e potássio juntamente da presença ou ausência de aplicação de adubo foliar.

O clima da região é do tipo Aw, definido como tropical úmido com estação chuvosa no verão e seca no inverno, segundo classificação de Köppen, apresentando temperatura, precipitação e umidade relativa média anual de $25^{\circ} \mathrm{C}$, $1313 \mathrm{~mm}$ e $70,8 \%$, respectivamente (PORTUGUAL et al., 2015).

No gráfico 1, encontra-se os dados de precipitação, temperatura máxima e 
mínima mensal registrados no posto meteorológico da Fazenda de Ensino, Pesquisa e Extensão, localizado próximo a área experimental, durante a realização dos experimentos.

O solo da área experimental de acordo com o Sistema brasileiro de classificação de solos vigente é um Latossolo Vermelho Distrófico típico $(\mathrm{LVd})$ de textura argilosa (EMBRAPA, 2013).
Antes da instalação dos experimentos, foi realizada uma amostragem do solo no local de cada experimento na camada de $0,0-0,2 \mathrm{~m}$ de profundidade para determinação das características químicas dos mesmos (Tabela 1). O método de determinação utilizado foi o Mehlich-1 (EMBRAPA, 1997).

Tabela 1. Resultados da análise química do solo, amostrados na profundidade de $0,0-0,20 \mathrm{~m}$ no local de cada experimento, antes da instalação dos mesmos

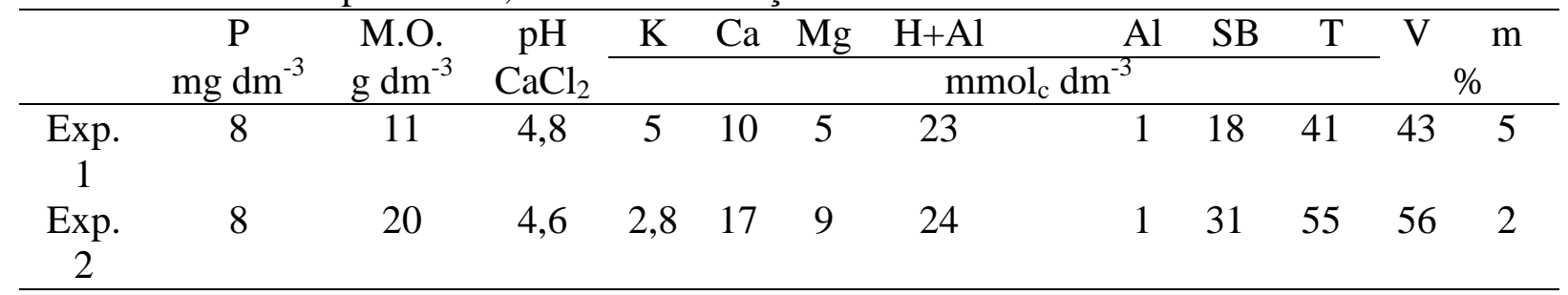

Em ambos os experimentos, o sistema de plantio adotado foi o convencional, preparado com grade pesada e niveladora, adequando o solo para receber sementes, antecedente a cada época de semeadura.

A variedade utilizada foi a IAC Tatu ST, lançada em 2000 pelo Instituto Agronômico de Campinas, é um material genético correspondente a tradicional cultivar Tatu, do tipo Valência, amplamente difundida no Brasil, de porte ereto, ciclo precoce (90 a 100 dias), rendimento de grãos de aproximadamente $70 \%$ e produtividade de 2 a $3 \mathrm{t} \mathrm{ha}^{-1}$.

As doses de fósforo e potássio avaliadas $\quad\left(60 \quad\right.$ e $\quad 20 \quad \mathrm{~kg} \quad \mathrm{ha}^{-1}$, respectivamente), foram baseadas nos resultados da análise química do solo da área experimental, objetivando obter uma produtividade de 1500 a $3000 \mathrm{~kg} \mathrm{ha}$. Também foi avaliada a ausência de adubação e o dobro das doses recomendadas.

As semeaduras foram realizadas no dia 16 de junho e 14 de novembro de 2006 , respectivamente para o experimento 1 e 2 , em sulcos previamente abertos, espaçados de 0,9 m entre si. Após a demarcação das parcelas, foram aplicadas as referidas doses de fósforo e potássio em suas respectivas parcelas de forma manual e uma posterior incorporação dos adubos, com auxílio de um sacho.

As fontes de fósforo e potássio utilizadas foram o superfosfato simples e o cloreto de potássio, respectivamente.

Logo após a incorporação, realizouse a semeadura de forma manual, colocando-se em média, 28 sementes por metro de sulco.

A germinação ocorreu respectivamente em 30 de junho e 22 de novembro de 2006.

O adubo foliar foi aplicado com auxílio de um pulverizador costal, equipado com bico tipo leque 110-03, calibrado para aplicação de $130 \mathrm{~L} \mathrm{ha}^{-1}$ de calda, sendo duas aplicações por experimento, realizadas aos 51 e 71 dias após emergência (DAE) no experimento 1 e 31 e 52 DAE no experimento 2, em ambos casos na concentração de 1,0 $\mathrm{L} \mathrm{ha}^{-1}$ (recomendação para a cultura, vide bula).

O produto comercial Flonergan ${ }^{\circledR}$ foi utilizado como adubo foliar e apresenta em sua constituição: $\mathrm{P}_{2} \mathrm{O}_{5}(8 \%), \mathrm{K}_{2} \mathrm{O}(8 \%)$, $\mathrm{N}(5 \%), \mathrm{S}(2,5 \%), \mathrm{Ca}(1,0 \%), \mathrm{Zn}(1,0 \%)$, $\mathrm{Mg}(0,5 \%), \mathrm{B}(0,5 \%), \mathrm{Mn}(0,5 \%), \mathrm{Cu}$ $(0,2 \%)$ e Mo $(0,1 \%)$.

$\mathrm{O}$ delineamento experimental utilizado foi em blocos casualizados em 
um esquema fatorial $3 \times 3 \times 2$, com quatro repetições, sendo 3 doses de adubo fosfatado $\left(0,60\right.$ e $120 \mathrm{~kg} \mathrm{ha}^{-1}$ de $\left.\mathrm{P}_{2} \mathrm{O}_{5}\right)$ e 3 doses de adubo potássico $\left(0,20\right.$ e $40 \mathrm{~kg} \mathrm{ha}^{-}$ ${ }^{1}$ de $\mathrm{K}_{2} \mathrm{O}$ ) aplicados via solo em momento antecedente a semeadura, associados a presença e ausência de adubação foliar (1 $\mathrm{L} \mathrm{ha}^{-1}$ ) durante a fase vegetativa da cultura.

As parcelas experimentais, com os tratamentos doses de fósforo e potássio, possuíam 4 linhas com $10 \mathrm{~m}$ de comprimento. No sentido transversal, cada parcela foi subdividida para implantação dos tratamentos sem e com adubação foliar. Sendo assim, cada parcela passou a ter 4 linhas com $5 \mathrm{~m}$ de comprimento, sendo considerado com área útil, as duas linhas centrais com $3 \mathrm{~m}$ de comprimento.

As sementes foram tratadas com fungicida a base de carboxin + thiram na dose de $50+50 \mathrm{~g}$ de i.a. para cada $100 \mathrm{~kg}$ de sementes.

Os tratos culturais, tais como manejo de plantas daninhas, pragas e doenças foram realizados de acordo com as recomendações para a cultura, procurando manter elevado nível de sanidade da cultura. Para o controle de tripes foi utilizado o princípio ativo Perfektion ${ }^{\circledR}$ na concentração de $400 \mathrm{~g} \mathrm{~L}^{-1}$, utilizado uma dosagem de 240 g i.a. ha ${ }^{-1}$. Para o controle de doenças foliares, foram realizadas pulverizações intercaladas, a base de isothalonil e pyraclostrobin + epoxiconazole.

Ambos os experimentos foram instalados em área irrigada por pivô

\section{RESULTADOS E DISCUSSÃO}

Na Tabela 2 encontram-se as médias do rendimento, massa de 100 grãos, produtividade de vagens e os valores de F, obtidos na análise estatística do experimento 1.

Verifica-se para rendimento de benefício que os tratamentos não proporcionaram diferença significativa central, portanto, quando necessário, foi realizada a irrigação para suplementação hídrica, principalmente no primeiro experimento que subsistiu a uma época de estiagem.

Foram avaliadas as características agronômicas em ocasião à colheita, amostrando 5 plantas seguidas de uma linha da área útil de cada parcela. Nessas plantas, em laboratório, foi avaliada a massa de 100 grãos e rendimento em grãos (relação entre a massa de vagens e de sementes obtidas nessas 5 plantas). Também foi avaliada a produtividade de vagens, que por ocasião da maturação, foram arrancadas e levadas para secagem em terreiro. Após a secagem, foi feito o despencamento das vagens e pesagem das mesmas, sendo a seguir, determinado a produção de vagens por hectare. As colheitas foram realizadas em 20 de novembro de 2006 e 23 de fevereiro 2007, respectivamente para o experimento 1 e 2 .

As médias do presente trabalho foram sujeitas a análise de homocedasticidade por meio do teste de Hartley $(p \leq 0,05)$. Os resultados foram submetidos à análise de variância ANOVA pelo teste $\mathrm{F}(p \leq 0,05)$, e, quando houve diferença significativa, realizou-se o estudo de regressão polinomial $(p \leq 0,05)$ para os fatores quantitativos e o teste de Tukey $(p \leq 0,05)$ para os fatores qualitativos. $\mathrm{O}$ programa estatístico utilizado foi o

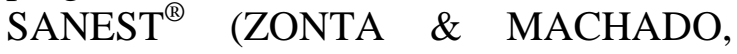
1991).

entre os fatores estudados. Conforme descrito anteriormente, essa variedade possui rendimento de grão de aproximadamente $70 \%$, portanto, os valores obtidos estão próximos ao estabelecido. 
Tabela 2. Valores de F e médias de rendimento de grãos, massa de 100 grãos e produtividade de grãos de amendoim, em função de doses de P e K e adubo foliar (Experimento 1).

\begin{tabular}{|c|c|c|c|}
\hline Tratamentos & $\begin{array}{c}\text { Rendimento } \\
(\%)\end{array}$ & $\begin{array}{c}\text { Massa de } 100 \text { grãos } \\
(\mathrm{g})\end{array}$ & $\begin{array}{c}\text { Produtividade } \\
\left(\mathrm{kg} \mathrm{ha}^{-1}\right)\end{array}$ \\
\hline \multicolumn{4}{|l|}{ Doses de $\mathrm{P}_{2} \mathrm{O}_{5}$} \\
\hline 0 & 66,7 & 44,4 & 1645 \\
\hline 60 & 66,4 & 42,9 & 1731 \\
\hline 120 & 68,1 & 39,0 & 1805 \\
\hline \multicolumn{4}{|l|}{ Doses de $\mathrm{K}_{2} \mathrm{O}$} \\
\hline 0 & 67,0 & 42,9 & 1660 \\
\hline 20 & 67,9 & 42,7 & 1783 \\
\hline 40 & 66,4 & 40,7 & 1738 \\
\hline \multicolumn{4}{|l|}{ Adubo Foliar } \\
\hline Ausência & 66,8 & 41,9 & 1726 \\
\hline Presença & 67,4 & 42,3 & 1728 \\
\hline \multicolumn{4}{|l|}{ Teste F } \\
\hline Fósforo (P) & $1,84^{\mathrm{ns}}$ & $8,63^{\text {** }}$ & $1,04^{\mathrm{ns}}$ \\
\hline Potássio (K) & $1,28^{\mathrm{ns}}$ & $1,56^{\mathrm{ns}}$ & $0,64^{\mathrm{ns}}$ \\
\hline Adubo foliar (AF) & $0,59^{\mathrm{ns}}$ & $0,14^{\mathrm{ns}}$ & $0,00^{\mathrm{ns}}$ \\
\hline $\mathrm{P} \times \mathrm{K}$ & $1,28^{\mathrm{ns}}$ & $0,37^{\mathrm{ns}}$ & $1,30^{\mathrm{ns}}$ \\
\hline $\mathrm{P} \times \mathrm{AF}$ & $0,07^{\mathrm{ns}}$ & $4,52^{*}$ & $0,80^{\mathrm{ns}}$ \\
\hline $\mathrm{K} \times \mathrm{AF}$ & $0,36^{\mathrm{ns}}$ & $1,27^{\mathrm{ns}}$ & $0,70^{\mathrm{ns}}$ \\
\hline $\mathrm{P} \times \mathrm{K} \times \mathrm{AF}$ & $0,90^{\mathrm{ns}}$ & $2,74^{\mathrm{ns}}$ & $0,74^{\mathrm{ns}}$ \\
\hline \multicolumn{4}{|l|}{ Fósforo } \\
\hline RL & $2,22^{\mathrm{ns}}$ & $1,36^{\mathrm{ns}}$ & $2,08^{\mathrm{ns}}$ \\
\hline RQ & $1,46^{\mathrm{ns}}$ & $15,89^{* *}$ & $0,0^{\mathrm{ns}}$ \\
\hline \multicolumn{4}{|l|}{ Potássio } \\
\hline RL & $0,52^{\mathrm{ns}}$ & $2,58^{\mathrm{ns}}$ & $0,50^{\mathrm{ns}}$ \\
\hline RQ & $2,05^{\mathrm{ns}}$ & $0,54^{\mathrm{ns}}$ & $0,78^{\mathrm{ns}}$ \\
\hline $\mathbf{C V}$ & 4,81 & 10,98 & 22,12 \\
\hline
\end{tabular}

Pode-se observar que para o parâmetro massa de 100 grãos, houve interação significativa entre doses de fósforo $\mathrm{x}$ adubo foliar.

Verifica-se que na comparação de doses de fósforo dentro de cada nível de adubação foliar, apenas houve diferença significativa na ausência de dose de fósforo, destacando a influencia positiva da adubação foliar no aumento de massa de grãos da cultura. Quando avaliou-se a adubação foliar dentro de cada nível de doses de $\mathrm{P}$, observou-se que tanto na presença quanto ausência da adubação foliar, os dados se ajustaram a uma equação quadrática, obtendo-se ponto de máxima nas doses $70,26 \mathrm{~kg} \mathrm{ha}^{-1}$ e 82,31 kg $\mathrm{ha}^{-1}$, respectivamente, como encontra-se expresso na Figura 2. 


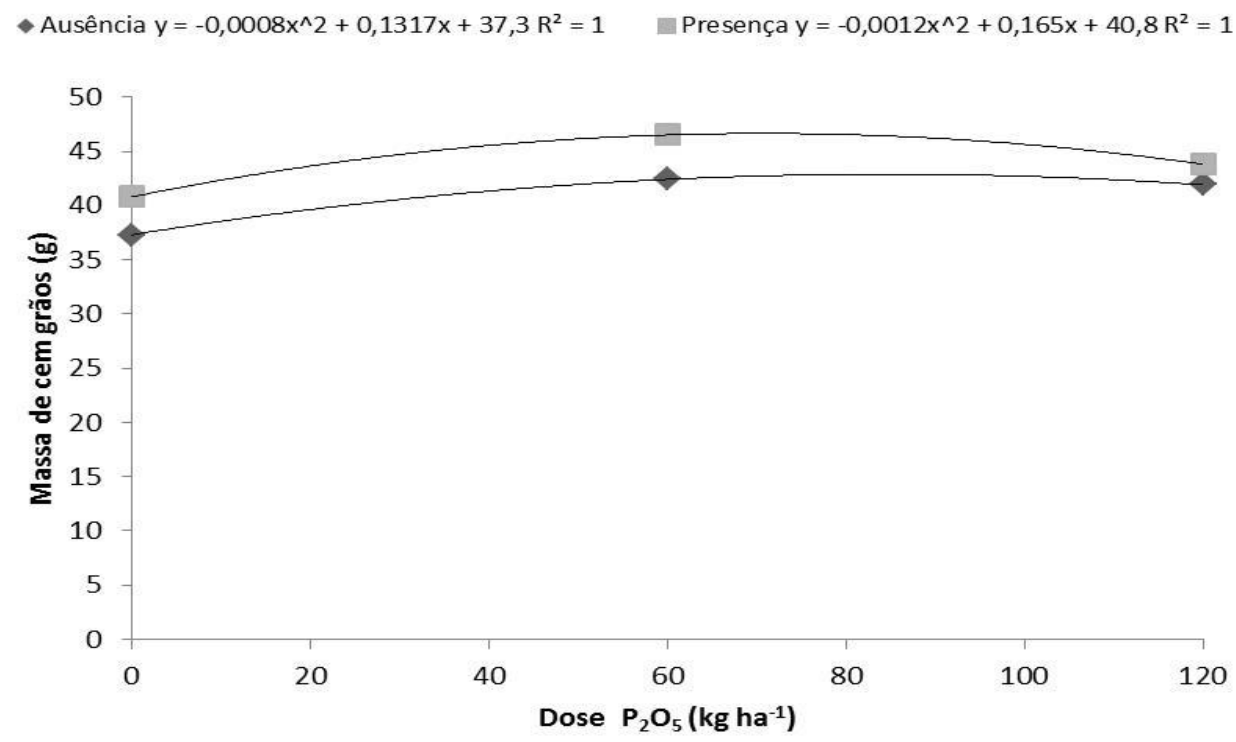

Figura 1. Desdobramento da interação $P$ x AF, significativa para a massa de 100 grãos de amendoim.

O fósforo é um elemento essencial para o aumento de produtividade das culturas, uma vez que faz parte da estrutura do ATP (adenosina tri-fosfato), fonte de energia para a planta, a qual é convertida na garantia do seu potencial produtivo. $\mathrm{O}$ fósforo se encontra também presente na estrutura do DNA, RNA e participa na duplicação celular e fotossíntese, sendo assim, ele está relacionado diretamente com o crescimento da planta. Mediante a adição de fósforo ao sistema, desde que em quantidades equilibradas, espera-se um aumento na atividade metabólica e fisiológica da planta (DUARTE et al., (2016).

A adubação foliar aliada a uma dose equilibrada de fósforo na semeadura pode ser uma alternativa viável no aumento de produtividade da cultura, uma vez que a mesma pode atuar como adubação de correção, fornecendo nutrientes para a cultura num momento de maior necessidade (VERDIN FILHO et al., 2013).

A produção final de grãos não foi influenciada pelos tratamentos. Segundo CONAB (2017), a média nacional de produção de amendoim em vagens, na safra 2015/16, foi de $3305 \mathrm{~kg} \mathrm{ha}^{-1}$, valores esses muito acima do observado nesse experimento.
Considerando-se apenas o amendoim cultivado no período de final de verão e outono, a média nacional obtida foi de $2403 \mathrm{~kg} \mathrm{ha}^{-1}$. A variedade IAC Tatu - ST, segundo Godoy et al. (2003) possui potencial de produção médio de $2,88 \mathrm{t} \mathrm{ha}^{-1}$, portanto, acima do obtido nesse experimento.

Segundo Raij et al. (1996), o solo da área experimental apresentava teor de fósforo e potássio considerados de baixos a médios para a cultura. Segundo Hernandez et al. (1993), as maiores produtividades de grãos foram quando utilizaram as doses de $30 \mathrm{~kg} \mathrm{ha}^{-1}$ de $\mathrm{P}_{2} \mathrm{O}_{5}$ e $20 \mathrm{~kg} \mathrm{ha}^{-1}$ de $\mathrm{K}_{2} \mathrm{O}$, sem diferenças significativas das outras doses utilizadas.

Também é comentado por estes mesmos autores que a cultura é pouco responsiva a fertilização mineral. Por estar sendo cultivada há vários anos, o solo da área experimental já apresentava um bom nível de fertilidade, principalmente em relação ao potássio, fazendo com que a cultura não respondesse as doses de nutrientes utilizados.

Schimann (1963), afirma que no estado de São Paulo, os solos cultivados com amendoim são pobres em fósforo, e quando este é utilizado na cultura, é considerado como principal fator de rendimento da produtividade, principalmente por sua alta capacidade de 
extração de nutrientes em baixa concentração. A baixa resposta da cultura a fertilizantes, também é comentada por Gerin et al. (1996).
$\mathrm{Na}$ Tabela 3, encontram-se os resultados obtidos na análise estatística dos dados obtidos no Experimento 2.

Tabela 3. Valores de $\mathrm{F}$ e médias de rendimento de grãos, massa de 100 grãos e produtividade de grãos de amendoim em função de doses de $\mathrm{P}$ e K e adubo foliar (Experimento 2).

\begin{tabular}{|c|c|c|c|}
\hline Tratamentos & $\begin{array}{c}\text { Rendimento } \\
(\%)\end{array}$ & $\begin{array}{c}\text { Massa de } 100 \text { grãos } \\
(\mathrm{g})\end{array}$ & $\begin{array}{c}\text { Produtividade } \\
\left(\mathrm{kg} \mathrm{ha}^{-1}\right)\end{array}$ \\
\hline \multicolumn{4}{|l|}{ Doses de $\mathrm{P}_{2} \mathrm{O}_{5}$} \\
\hline 0 & 48,2 & 31,1 & 1035 \\
\hline 60 & 46,5 & 31,4 & 913 \\
\hline 120 & 48,1 & 30,9 & 987 \\
\hline \multicolumn{4}{|l|}{ Doses de $\mathrm{K}_{2} \mathrm{O}$} \\
\hline 0 & 47,0 & 30,8 & 989 \\
\hline 20 & 48,3 & 31,9 & 1061 \\
\hline 40 & 47,5 & 30,8 & 886 \\
\hline \multicolumn{4}{|l|}{ Adubo Foliar } \\
\hline Ausência & 47,8 & 30,9 & 869 b \\
\hline Presença & 47,4 & 31,3 & $1088 \mathbf{a}$ \\
\hline \multicolumn{4}{|l|}{ Teste F } \\
\hline Fósforo (P) & $0,55^{\mathrm{ns}}$ & $0,37^{\mathrm{ns}}$ & $0,58^{\mathrm{ns}}$ \\
\hline Potássio (K) & $0,28^{\mathrm{ns}}$ & $2,58^{*}$ & $1,19^{\mathrm{ns}}$ \\
\hline Adubo foliar (AF) & $0,05^{\mathrm{ns}}$ & $0,84^{\mathrm{ns}}$ & $5,58^{*}$ \\
\hline $\mathrm{P} \times \mathrm{K}$ & $0,86^{\mathrm{ns}}$ & $1,56^{\mathrm{ns}}$ & $0,06^{\mathrm{ns}}$ \\
\hline $\mathrm{P} \times \mathrm{AF}$ & $0,6^{\mathrm{ns}}$ & $1,17^{\mathrm{ns}}$ & $0,38^{\mathrm{ns}}$ \\
\hline $\mathrm{K} \times \mathrm{AF}$ & $2,47^{\mathrm{ns}}$ & $0,03^{\mathrm{ns}}$ & $1,13^{\mathrm{ns}}$ \\
\hline $\mathrm{P} \times \mathrm{K} \times \mathrm{AF}$ & $0,80^{\mathrm{ns}}$ & $1,09^{\mathrm{ns}}$ & $1,48^{\mathrm{ns}}$ \\
\hline \multicolumn{4}{|l|}{ Fósforo } \\
\hline RL & $0,0^{\mathrm{ns}}$ & 0,05 & 0,17 \\
\hline RQ & $1,10^{\mathrm{ns}}$ & 0,69 & 0,98 \\
\hline \multicolumn{4}{|l|}{ Potássio } \\
\hline RL & $0,08^{\mathrm{ns}}$ & $0,0^{\mathrm{ns}}$ & $0,81^{\mathrm{ns}}$ \\
\hline RQ & $0,47^{\mathrm{ns}}$ & $5,17^{*}$ & $1,57^{\mathrm{ns}}$ \\
\hline $\mathrm{CV}$ & 13,09 & 6,34 & 40,20 \\
\hline
\end{tabular}

Médias seguidas de letras distintas nas linhas diferem entre si pelo teste de Tukey ao nível de $5 \%$ de probabilidade

Para rendimento de benefício, não se observou influência de nenhum fator causal utilizado, assim como verificado no experimento 1. Verifica-se que para o parâmetro massa de 100 grãos, houve influência significativa das doses de potássio, ajustando-se a uma equação quadrática obtendo ponto de máxima na dose de 19,64 $\mathrm{kg} \mathrm{ha}^{-1}$ (Figura 2). 


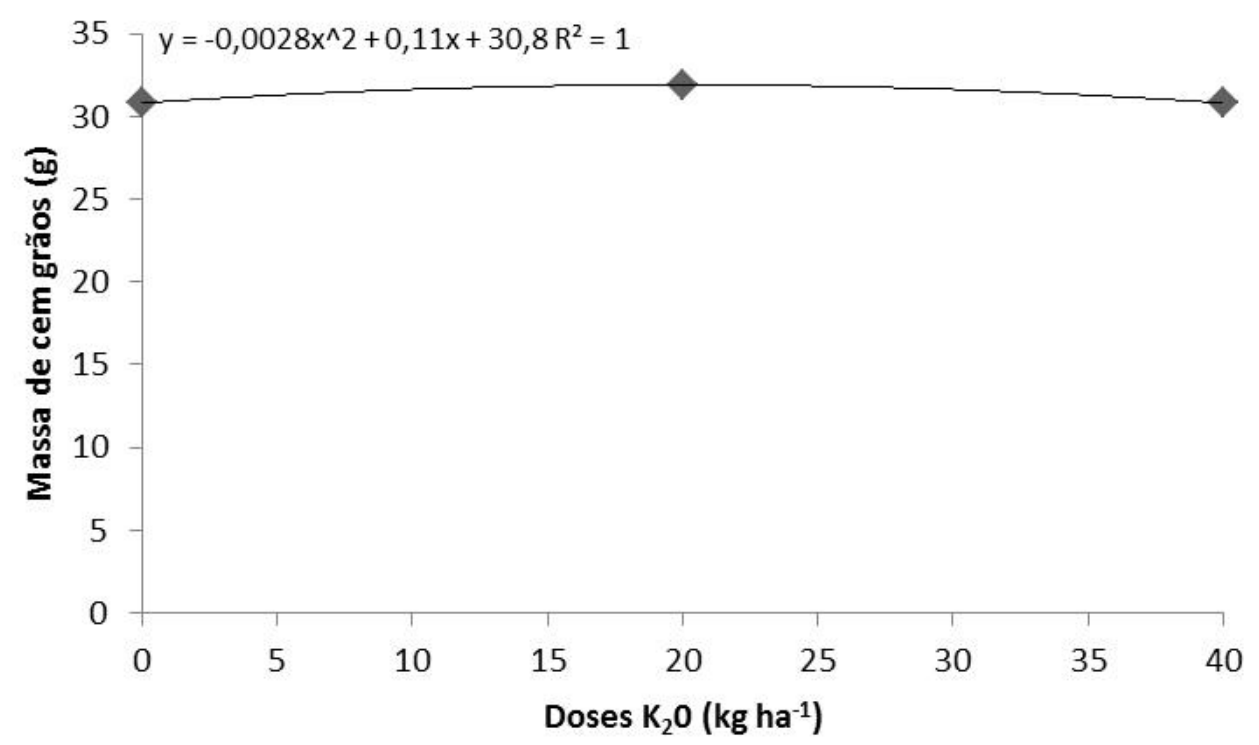

Figura 2. Massa de 100 grãos de amendoim em função de doses de potássio.

Os teores de potássio encontrados no solo na área do segundo experimento são considerados baixos para a cultura, sendo, portanto, necessário à adição de potássio ao sistema. Este elemento está condicionado às várias funções no metabolismo vegetal, sendo ativador enzimático durante $o$ processo de fotossíntese, respiração e síntese de proteínas, atuando também na abertura estomática, no transporte via floema, na osmorregulação e na extensão celular (PRADO, 2008; MELO et al., 2010).

Os valores obtidos para os parâmetros avaliados foram inferiores aos observados no Experimento 1 e pelas características apresentadas desta variedade.

As condições ambientais durante a condução do Experimento 2 foram extremamente favoráveis ao desenvolvimento das plantas, porém sem reflexos positivos na produtividade. Fatores como excesso de chuva durante o

\section{CONCLUSÕES}

Mesmo em solos de baixa a média fertilidade, não há aumento de produtividade de grãos de amendoim até as doses de fósforo e potássio utilizadas. mês de janeiro foram prejudiciais na formação de vagens e sementes, levando a baixa intensidade luminosa em período critico podendo ter levado a produções mais baixas e de grãos menores e consequentemente a um menor rendimento de grãos e produtividade.

Quanto à produtividade de grãos, verifica-se que houve influência significativa da adubação foliar, onde a presença da mesma propiciou aumento na produtividade da cultura. Não houve interação entre as doses de fósforo e potássio utilizadas e nem mesmo efeito destes fatores isolados quanto e este parâmetro estudado, fato este associado à baixa responsividade da cultura a adubação mineral direta (MANTOVANI et al., 2013). Em relação à presença do adubo foliar, o efeito benéfico pode estar associado ao coquetel de nutrientes presentes na formulação do produto, o qual pode ter suprido a exigência da cultura em um período de maior necessidade.
A adubação foliar mineral pode ser utilizada em períodos de maior necessidade nutricional da cultura. 


\section{REFERÊNCIAS BIBLIOGRÁFICAS}

CONAB - Companhia Nacional de Abastecimento. Amendoim, Safra 2015/2016. Quarto levantamento, janeiro $2016 . \quad$ Disponível em: <http://www.conab.gov.br/>. Acesso em: 12 janeiro 2017.

DUARTE, C. F. D.; PAIVA, L. M.; FERNANDES, H. J., CASSARO, L. H.; BREURE, M. F.; PROCHERA, D. L., BISERRA, T. T.; Capim-piatã adubado com diferentes fontes de fósforo. Investigação, ed 15, n. 4, 2016.

EMBRAPA. Centro Nacional de Pesquisa de Solos.; Manual de métodos de análise de solo. Rio de Janeiro, ed 2: 212p, 1997.

EMPRAPA - Empresa Brasileira de Pesquisa Agropecuária; Sistema brasileiro de classificação de solos, Brasília, DF. ed 3: 356p, 2013.

GERIN, M. A. N.; FEITOSA, C. T.; RODRIGUES FILHO, S.O.; PEREIRA, J. C. V. N. A.; NOGUEIRA, S. S. S.; IGUES, T.; Adubação do amendoim (arachis hypogea L.) em área de reforma de canavial. Scientia Agrícola, Piracicaba, v. 53(1): 84-87, 1996.

GRANT, C. A.; FLATEN, D. N.; TOMASIEWICZ D. J.; SHEPPARD, S. C.; A Importância do fósforo no desenvolvimento inicial da planta. Informações agronômicas, Piracicaba, SP. Ed 95: 1-5, 2001.

GODOY, I. J.; MORAES, S. A.; KASAI, F. S.; MARTINS A. L. M.; PEREIRA, J. C. V. N. ; MORARES, A. R. A.; TEIXEIRA, J. P. F.; Cultivares IAC de amendoim. O agronômico, Campinas, SP, v. 55 (1): 26-29, 2003.

HENN, P. U.; Benefícios da Rotação de Cana com Amendoim. Coplana. 2013. Disponível em: <http://www.assocana.com.br/restrito/04_e _05.12.13_12.Paulo_Umberto_Henn.pdf $>$ Acesso em : 13 março 2017.

HESS, L; Potássio com aminoácidos melhora o enchimento da cebola. Campo
\& Negócios, Uberlândia, MG, ed 116, 2015.

MACÊDO, M. H. G.; Amendoim. CONAB - Companhia Nacional de Abastecimento, Brasília, DF, 1-15p, 2006.

MANTOVANI, J. P. M.; CALONEGO, J. C.; FOLONI, J. S.; Adubação foliar de boro em diferentes estádios fenológicos da cultura do amendoim. Revista Ceres, ed. 60, n. 2: 270-278p, 2013.

MARQUES, D. J; BIANCHINI, H. C.; ROEWER L. A.; Fosfito de potássio contribui para enchimento de grãos. Campo \& Negócios, Uberlândia, MG ed. 141, 2014.

MARTINS, R.; Amendoim: recuperação e recorde de produção na safra paulista 2014/2015. $2015 . \quad$ Disponível em: <http://www.iea.sp.gov.br/out/LerTexto.ph p?codTexto $=13678>$. Acesso em: 12 janeiro 2017.

MELO, A. S. de; FERNANDES, P. O.; SOBRAL, L. F.; BRITO, M. E. B.; DANTAS, J. D. M.; Crescimento, produção de biomassa e eficiência fotossintética da bananeira sob fertirrigacão com nitrogênio e potássio. Revista Ciência Agronômica, ed.41: 417426p, 2010.

PORTUGAL, J. R.; PERES, A. R.; RODRIGUES, R. A. F. (2015); Aspectos climáticos no feijoeiro. In: ARF, O.; LEMOS, L. B.; SORATTO, R. P.; FERRARI, S.; (Eds.) Aspectos gerais da cultura do feijão (Phaseolus vulgaris $L$.). Botucatu: FEPAF, cap. 4:65-75.

PRADO, R. M.; Nutrição de plantas. São Paulo: UNESP, 407p, 2008.

RAIJ, B van; CANTARELLA, H.; QUAGGIO, I. A.; FURLANI, A. M. C.; Recomendação de adubação e calagem para o estado de São Paulo, Campinas: Instituto Agronômico, ed 2: 285p, 1996.

SCHIMANN, W.; NEPTUNE, A. M. L.; SABINO, N. P.; Acumulação de macronutrientes pelo amendoim (Arachis 
hipogaea L.) cultivado em outono na época da seca. Anais da Escola Superior de Agricultura Luiz de Queiroz, Piracicaba, ed 37: 393-409p, 1963.

VERDIN FILHO, A. C.; BRINATE, S. V. B.; TOMAZ, M. A.; NOGUEIRA, N. O.; SOUZA, M. L.; ADUBAÇÃO FOLIAR
DO CAFEEIRO. Tópicos Especiais em Produção Vegetal IV, 403p, 2013.

ZONTA, E. P.; MACHADO, A. A.; SANEST: Sistema de análise estatística para microcomputadores. Pelotas: UFPEL, 120p, 1991. 